\title{
Effect of different cooking conditions on antioxidant properties of some cucurbit vegetables
}

\author{
N. KARMAKAR, B.B. ABUJ, S. OJHA AND S. TRIPATHI
}

Received: 17.08.2017; Revised: 10.11.2017; Accepted: 25.11.2017

See end of the paper for authors' affiliations

\section{N. KARMAKAR}

Department of Soil Science and

Agricultural Chemistry, Navsari

Agricultural University, NAVSARI

(GUJARAT) INDIA

Email : nilimanau13@gmail.com
DABSTRACT : Effects of pressure cooker and microwave cooking methods on total antioxidant activity (AA), Vitamin C, phenols, flavonoids, anthocyanin and total carotenoids different types of gourd vegetables like cucumber, pumpkin, bottle gourd, bitter gourd, pointed gourd and spine gourd were collected from local market of Navsari. The time length was standardized for different length of time in pressure cooker and microwave. The methanolic extracts of different raw and cooked (7, 10 and $15 \mathrm{~min}$ ) both in pressure and microwave cooked vegetables were tested. The result revealed higher percentage of loss of antioxidants under microwaving compared to pressure cooking.There four it is clear that bitter gourd is the vegetable which is containing the highest antioxidant activity. This experiment also clarified the fact that most of the vegetable, microwave heating for 7 minutes and pressure cooking for 10 minutes gives the best result as this food material contains possible higher amount of antioxidant activity with proper cooking standard.

KEY WORDS: Gourd, Pressure cooked, Microwave, Antioxidant, Cooking time

- HOW TO CITE THIS PAPER : Karmakar, N., Abuj, B.B., Ojha, S. and Tripathi, S. (2017). Effect of different cooking conditions on antioxidant properties of some cucurbit vegetables. Asian J. Home Sci., 12 (2) : 614-621, DOI: 10.15740/HAS/AJHS/12.2/614-621. 